\title{
Sustained Activation of Hippocampal Lp-Type Voltage-Gated Calcium Channels by Tetanic Stimulation
}

\author{
Jessica M. Schjött and Mark R. Plummer \\ Rutgers University, Department of Cell Biology and Neuroscience, Nelson Laboratories, \\ Piscataway, New Jersey 08854-8082
}

The molecular heterogeneity of voltage-gated calcium channels is mirrored by extensive biophysical diversity. Subtypeselective antagonists have been used to place different kinds of calcium channels in functional categories. Dihydropyridine (DHP) antagonists have been used, for example, to implicate L-type calcium channels in the induction of NMDA receptorindependent forms of synaptic plasticity. DHPs, however, do not discriminate between the recently identified Lp and Ls subtypes of L-type calcium channel. The different properties of the two kinds of L-type channels suggest that they may have different functional roles. Ls channels are comparable with cardiac L-type channels, whereas Lp channels show lowthreshold voltage-dependent potentiation. To clarify the potential roles of $\mathrm{Lp}$ and Ls channels in the induction of synaptic plasticity, we studied the responses of these channels to trains of action potentials. The frequency and duration of the trains

Calcium entry into neurons is an essential trigger for many forms of synaptic plasticity (for review, see Malenka and Nicoll, 1993). The flux of extracellular calcium into cells is accomplished via ligand- or voltage-gated calcium-permeable ion channels such as the NMDA receptor channel or voltage-gated calcium channels. The involvement of these ion channels in the induction of synaptic plasticity has been demonstrated with selective antagonists. AP-5, a specific blocker of NMDA receptors, prevents induction of long-term potentiation (LTP) in hippocampal CA1 pyramidal neurons (Collingridge et al., 1983; Harris et al., 1984), and the calcium channel antagonists nifedipine and nimodipine can prevent induction of NMDA receptor-independent LTP in CA1 (Grover and Teyler, 1990), CA3 (Kapur et al., 1998), and amygdala neurons (Weisskopf et al., 1999). Nifedipine and nimodipine, dihydropyridine (DHP) compounds, are selective antagonists of L-type voltage-gated calcium channels (for review, see Triggle, 1999), thus implicating this channel type in the regulation of NMDA receptor-independent forms of synaptic plasticity (Johnston et al., 1992).

We (Kavalali and Plummer, 1994, 1996; Kavalali et al., 1997a) and others (Forti and Pietrobon, 1993; Hivert et al., 1999) have suggested that there are multiple functional kinds of L-type channels that differ in their conductance and kinetic properties.

Received Jan. 11, 2000; revised April 3, 2000; accepted April 12, 2000.

This study was supported by the National Institutes of Health Grant NS 34061. We are grateful to Drs. R. L. Davis and S. B. Auerbach for helpful discussions and comments on this manuscript.

Correspondence should be addressed to Dr. Mark R. Plummer, Rutgers University, Nelson Laboratories, 604 Allison Road, Piscataway, NJ 08854-8082. E-mail: mplummer@rci.rutgers.edu.

Copyright (C) 2000 Society for Neuroscience $\quad 0270-6474 / 00 / 204786-12 \$ 15.00 / 0$ were chosen to mimic the stimuli used to induce changes in synaptic strength. Cell-attached single-channel recordings from cultured hippocampal neurons revealed that both Lp and Ls channels responded to these trains, but only $L p$ channels showed persistent activation that outlasted the train. The magnitude of Lp channel activity increased with increasing action potential frequency and train duration. Stimuli that reproduced the postsynaptic response to action potential trains were also examined, and Lp channels were found to show much greater responses than were Ls channels. These results suggest that the Lp channel may play a critical role in the induction of long-lasting changes in synaptic strength.

Key words: calcium channel; hippocampus; potentiation; long-term potentiation; synaptic plasticity; dihydropyridine; L-type
The primary criterion used to distinguish between types of L-type channels is the presence of repolarization reopenings, openings that occur subsequent to a depolarization and return to the holding potential.

The subtype of L-type channel that shows reopenings has been referred to as either the Lp channel (Kavalali and Plummer, 1994) or the "anomalous" L-type channel (Forti and Pietrobon, 1993) on the basis of different interpretations of the channel's voltage dependence. L p channels were named according to the voltage-dependent potentiation of their activity seen after conditioning depolarization. Anomalous L-type channels were named for their "bell"-shaped activation profile. At present, it is not known whether this distinction in nomenclature reflects yet further subdivisions in L-type channels that show repolarization reopenings or whether $\mathrm{Lp}$ and anomalous L-type channels are the same.

Regardless of the details of classification, it is clear that the activity of $\mathrm{Lp}$ channels is increased after depolarization. Moreover, relatively low-voltage stimuli can produce this potentiation (Kavalali and Plummer, 1996), leading to speculation that this channel type is involved in the induction of NMDA receptorindependent forms of synaptic plasticity. The goal of this study was to gain insight into this possibility by determining whether the L p channel can be activated by the same kinds of stimuli known to elicit changes in synaptic strength. We tested both presynaptic and postsynaptic equivalents of action potential train stimuli by synthesizing appropriate waveforms and examining the responses produced by these stimuli in cell-attached single-channel recordings of $\mathrm{Lp}$ channels. We found that $\mathrm{Lp}$ channels could be activated by these stimuli and were preferentially activated by them 
when compared with the responses of the more cardiac-like L-type calcium channel (Ls). Thus we provide support for the notion that Lp channels may be critically involved in the induction of NMDA receptor-independent forms of synaptic plasticity.

\section{MATERIALS AND METHODS}

Cell culture. Hippocampal cultures were grown as described previously (Levine et al., 1995). Briefly, hippocampi were obtained from embryonic day 18 Sprague Dawley rats and placed into cold PBS. Cells were triturated in $2 \mathrm{ml}$ of MEM with added glucose and $7.5 \%$ fetal bovine serum and plated on poly-D-lysine-coated Petri dishes at a final density of $10^{6}$ cells $/ 35 \mathrm{~mm}$ dish. Cultures were maintained in serum-free medium (SFM) at $37^{\circ} \mathrm{C}$ in a $95 \%$ air $/ 5 \% \mathrm{CO}_{2}$ humidified incubator. SFM consisted of a 1:1 (v/v) mixture of Ham's F-12 and Eagle's minimum essential medium and was supplemented with insulin $(25 \mu \mathrm{g} / \mathrm{ml})$, transferrin $(100 \mu \mathrm{g} / \mathrm{ml})$, putrescine $(60 \mu \mathrm{M})$, progesterone $(20 \mathrm{nM})$, selenium $(30 \mathrm{nM})$, glucose $(6 \mathrm{mg} / \mathrm{ml})$, and penicillin-streptomycin $(0.5 \mathrm{U} / \mathrm{ml}$ and $0.5 \mathrm{mg} / \mathrm{ml}$, respectively).

Recordings and experimental treatments. Voltage-clamp recordings were obtained from pyramidal-type cells after 3-21 d in vitro using standard techniques (Hamill et al., 1981). Cell-attached single-channel recordings were made with barium as the charge carrier (in mM, $20 \mathrm{BaCl}_{2}, 10$ TEA, 90 choline chloride, and 10 HEPES-TEAOH, pH 7.5), and a depolarizing bath solution was used to bring the intracellular potential to $\sim 0 \mathrm{mV}$ (in $\mathrm{mM}, 140 \mathrm{~K}$-gluconate, $10 \mathrm{HEPES}-\mathrm{KOH}$, and 5 EGTA, $\mathrm{pH} 7.5$ ). Unless otherwise specified, $1 \mu \mathrm{M}$ L-type channel agonist FPL 64176 (Zheng et al., 1991) was added to the bath solution to clarify the number and the types of calcium channels in the patch. Recordings were made with an Axopatch 200 amplifier (Axon Instruments, Foster City, CA). Data were sampled with an INDEC 15125 analog-to-digital converter (INDEC Systems, Capitola, CA) at $5 \mathrm{kHz}$ and filtered at $1 \mathrm{kHz}$. Voltage pulses were delivered at $5 \mathrm{sec}$ intervals. Linear leak and capacitive currents were subtracted digitally. All recording parameters were controlled by programs written in Borland $\mathrm{C}^{++}$using INDEC-supplied driver libraries.

Data analysis. Open times and open probabilities were obtained from sweeps idealized with a half-amplitude crossing criterion and cubic spline interpolation (Colquhoun and Sigworth, 1983). Overall open probability $\left(p_{\mathrm{o}}\right)$ in response to a particular stimulus was calculated by evaluating all applicable sweeps during the entire recording, including null sweeps. The total open time during the analyzed portion of the sweep was divided by the analysis time period. Incomplete channel openings, such as tail current openings, were included in the analysis. For patches that contained two of the same kind of channel, open probability was measured for both channels and divided by two. This assumes that the two channels have similar but independent gating characteristics and give values appropriate for a single channel. At least 20 , typically $50-80$, sweeps were used for each $p_{\mathrm{o}}$ calculation.

For analysis of open time, values were plotted on square root-log coordinates, and mean open times were estimated from the maximum likelihood fitting (Sigworth and Sine, 1987). The number of open time components used for fits was based on a previous study (Kavalali et al., 1997a). Data from all experiments were summed and treated as a single distribution. The summed distributions were compared statistically with the Kolmogorov-Smirnov test. Unless otherwise stated, statistical comparisons were made with the Student's $t$ test. Data analysis was accomplished with programs written in Microsoft Visual Basic.

$\mathrm{Lp}$ and Ls channels were identified according to criteria described previously (Kavalali and Plummer, 1994). In brief, Lp activity was identified by the presence of reopenings during repolarization to -70 $\mathrm{mV}$ after a voltage pulse to $-10 \mathrm{mV}$. When studied in the presence of FPL 64176, Lp channels could be further distinguished from Ls channels on the basis of unitary current amplitude and relatively shorter open times. Two kinds of recordings were selected for detailed analysis. The first was from patches that contained one to two of the same kind of channel, determined by the presence of superimposed openings of a single type. The second type of recording was from multichannel patches that contained both Lp and Ls channels (typically one to three Ls and one to two L p channels). These patches were used exclusively for studies of $\mathrm{Lp}$ reopenings because only $\mathrm{L} p$ channels are active after repolarization (Kavalali and Plummer, 1994). Patches containing non-DHPsensitive channels (e.g., T-, N-, and P-type channels that typically showed more openings when tested from a holding potential of $-90 \mathrm{mV}$ compared with $-40 \mathrm{mV}$ ) were not used.

\section{RESULTS}

As we have shown previously (Kavalali and Plummer, 1994, 1996; Kavalali et al., 1997a), cell-attached single-channel recordings from hippocampal neurons reveal two general classes of voltagegated calcium channel whose openings are prolonged by exposure to the L-type calcium channel agonist FPL 64176 (Fig. 1A,B). One type of channel, Ls, shows openings that are restricted to the test depolarization or are strict "tail currents" in which the abrupt change in driving force from the test potential to the holding potential elicits a large current through a channel that is already open (Fig. 1D). The second type of channel, Lp, opens during the test potential but can also reopen several times after the transmembrane voltage has been returned to the holding potential (Fig. 1C). A key distinction between Ls tail currents and Lp reopenings at $-70 \mathrm{mV}$ is that tail currents are relatively brief and are not interrupted by numerous brief closures. As described in detail in previous work (Kavalali and Plummer, 1994), the two channels also show characteristic differences in unitary conductance and mean open time in the presence of agonist (Fig. 1C,D).

The goal of this study was to gain insight into the functional roles of $\mathrm{Lp}$ and $\mathrm{Ls}$ channels by comparing their responses to physiologically relevant stimuli such as trains of action potentials in addition to the more standard square pulse voltage protocols. To accomplish this, synthetic waveforms were created in which action potentials were delivered at three different frequencies: 25 , 50, and $100 \mathrm{~Hz}$ (Fig. 2). The action potential used (Fig. 2, left) was based on those recorded from cultured hippocampal neurons with the whole-cell current-clamp technique. The holding potential was set to $-70 \mathrm{mV}$, and the interspike potential (the voltage between individual action potentials) was set to $-60 \mathrm{mV}$. Again, these values for the transmembrane voltage were chosen according to their general approximation of responses of hippocampal neurons to step current injection. The $100 \mathrm{~Hz}$ action potential train was tested because of its common usage as "tetanic" stimulation in the induction of long-term forms of synaptic plasticity (for review, see Bliss and Collingridge, 1993). The lower frequency trains were used for comparison with the higher frequency ones.

In the first part of this study, Lp and Ls activity was assessed during the repolarization portion of the stimulus (the period at the holding potential subsequent to the action potential trainsee Fig. $3 A$, dashed line). This approach allowed us to examine relatively long-lasting effects of action potential trains. We were not able to quantify channel activity during the action potential trains because the leak and capacitive currents could not be subtracted accurately. It is clear in the traces, however, that action potential trains elicited openings of both Ls and L p channels (Fig. $3 A, C)$. Repolarization activity was quantified as the open probability $\left(p_{\mathrm{o}}\right)$ by dividing the percent time that the channel was open by the total duration of the repolarization period. Thus both tail current openings and reopenings contributed to the measured $p_{\mathrm{o}}$.

When tested with action potential train stimuli, Lp and Ls channels showed different responses (Fig. 3). A $100 \mathrm{~Hz}$ train of action potentials, for example, caused $\mathrm{Lp}$ channels to show numerous reopenings after the cessation of the action potential train (Fig. $3 A$ ). Ls channels, however, in response to the same stimulus, showed only occasional tail current openings (Fig. 3C). This difference in channel kinetics was more evident in ensemble average currents that revealed a rapid decay of Ls current during repolarization compared with a slow decay of $\mathrm{Lp}$ current. To understand how Lp and Ls channel gatings were being affected by 
A - Before agonist

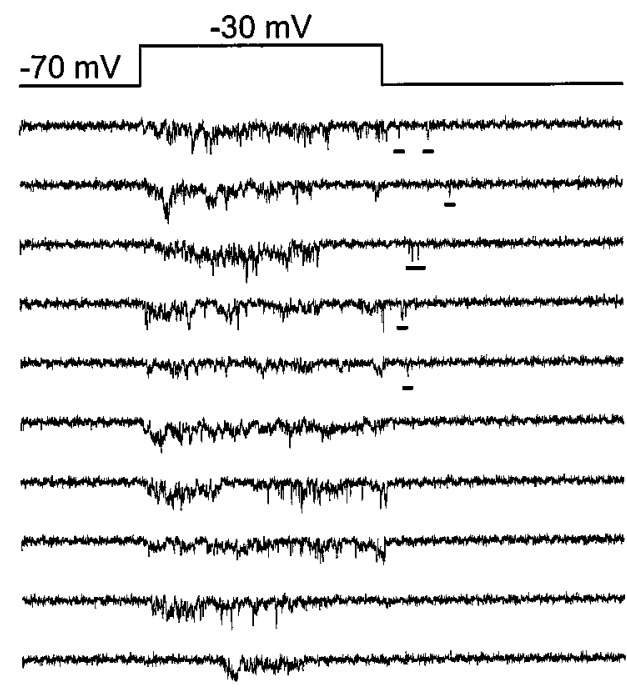

Figure 1. Lp and Ls channels show characteristic gating patterns in the presence or absence of agonist. $A$, Ten consecutive sweeps of a cell-attached recording from a hippocampal neuron in tissue culture. The patch contained multiple calcium channels; in the absence of agonist, openings were brief and poorly resolved. In this particular patch, repolarization reopenings (horizontal bars) were observed in some of the sweeps. B, Ten consecutive sweeps from the same patch illustrated in $A$ after addition of the L-type channel agonist FPL $64176(1 \mu \mathrm{M})$. Test pulse and repolarization reopening durations were both prolonged. $C$, Cell-attached recordings in the presence of agonist from a patch that contained two Lp channels Reopenings are shown in sweeps 1 (top), 3, and 5. D, Cell-attached recordings in the presence of agonist from a patch that contained two Ls channels. Tail current openings are shown in sweeps 1 and 3 . The dashed lines in both $C$ and $D$ indicate the amplitude of Ls channels under similar recording conditions. Note that the amplitudes of Lp openings were slightly smaller than those of Ls channels, as expected from the slightly smaller conductance of this channel type (Kavalali and Plummer, 1994). Also note the characteristic difference in agonist-induced open time between Lp and Ls channels.

\section{C - Lp channel}

\section{B - With agonist}
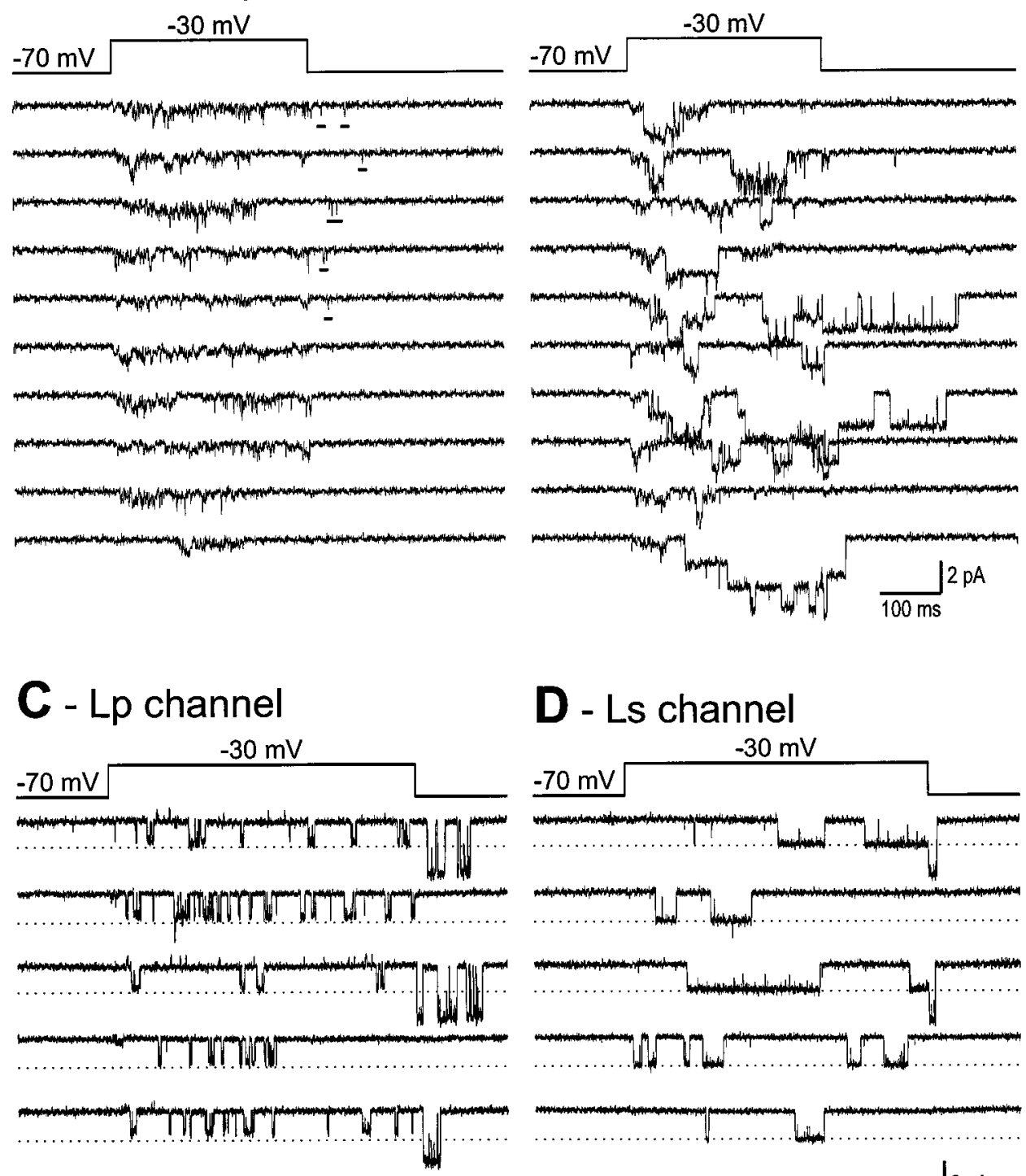

action potential trains, we compared, in the same recordings, responses to trains with responses to square pulse depolarizations to different test potentials (Fig. $3 B, D$ ). We found that square pulse depolarizations to relatively modest test potentials (less than or equal to $-30 \mathrm{mV}$ ) elicited reopenings and tails currents that were similar to the maximal response produced by the action potential trains. In addition to comparable levels of activity, there were no obvious differences in the pattern of openings or the latencies to the first opening. Therefore, action potential train stimuli did not appear to produce qualitatively different types of responses than did square pulse stimuli.

Quantification of Lp channel activity showed that action potential trains of increasing frequency produced greater levels of repolarization activity at $-70 \mathrm{mV}$ (Fig. $4 A$ ). The $100 \mathrm{~Hz}$ train, for example, caused an eightfold greater response than did the 25 $\mathrm{Hz}$ train $\left(p_{\mathrm{o}}=0.03 \pm 0.008\right.$ vs $\left.0.0036 \pm 0.002 ; p<0.01\right)$. As expected, square pulses with increasingly positive test potentials also produced progressively greater responses. Increasing the test potential from -40 to $-10 \mathrm{mV}$ caused a 24 -fold increase in reopenings $\left(p_{\mathrm{o}}=0.005 \pm 0.003\right.$ vs $\left.0.12 \pm 0.016 ; p<0.001\right)$. Quantification of Ls channel responses showed that the amount of activity elicited during the repolarization period was very low. Furthermore, none of the Ls channel responses to the different stimuli was significantly different ( $p>0.05$ for all comparisons). Nonetheless, trends similar to that seen for $\mathrm{Lp}$ channels were observed (Fig. 4B). Larger Ls channel responses were obtained with greater action potential frequencies or an increased magnitude of depolarization. Finally, comparison of Lp versus Ls channels revealed significant differences for all stimuli tested $(p<0.01)$ except for the smallest square pulse $(-40 \mathrm{mV} ; p>0.1)$ and the lowest-frequency action potential train $(25 \mathrm{~Hz} ; p>0.1)$.

Additional insight into the mechanism of $\mathrm{Lp}$ channel gating was obtained by comparing responses to the action potential trains and square voltage pulses. A significant difference between these two types of stimuli is that action potential trains briefly make the membrane potential very positive, even though the 
Single AP

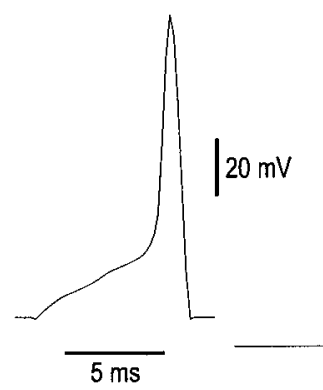

$25 \mathrm{~Hz}$

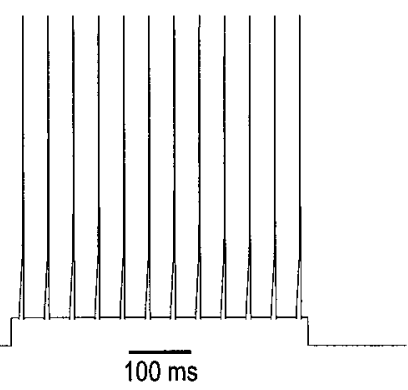

$50 \mathrm{~Hz}$

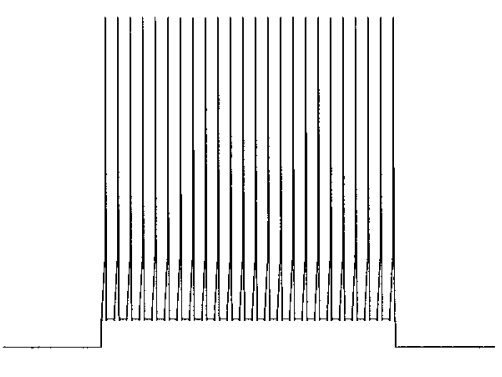

$100 \mathrm{~Hz}$

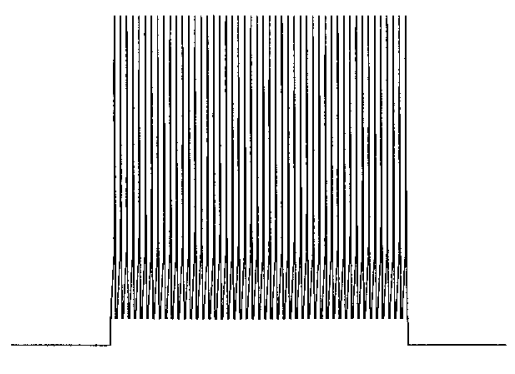

Figure 2. Stimulus templates used to study the responses of Lp and Ls calcium channels to trains of action potentials. The computer-generated waveforms were used to reproduce the general characteristics of trains of action potentials firing at defined frequencies. Left, Trace showing the model for an individual action potential. Its shape was based on whole-cell current-clamp recordings from cultured hippocampal neurons. Middle, Right, Traces showing action potential bursts of the indicated firing frequency. Each of the bursts was constructed using a series of the individual action potentials. The holding voltage was $-70 \mathrm{mV}$, the interspike voltage was $-60 \mathrm{mV}$, and each action potential peaked at $+47 \mathrm{mV}$. Note the difference in the timescale between the left and the remaining three traces. AP, Action potential.

average depolarization remains modest. To determine whether the briefly positive membrane potential had an effect on Lp channel gating, we calculated the average depolarization produced by each of the action potential trains and compared the response obtained with the action potential train with the response obtained with a square pulse of comparable average depolarization. For the 25,50 , and $100 \mathrm{~Hz}$ trains, the average depolarizations were approximately $-55,-51$, and $-41 \mathrm{mV}$, respectively. Each of these values was determined by integrating the area under the action potential burst portion of the waveform. Preliminary experiments showed that voltage pulses to $-50 \mathrm{mV}$ elicited essentially no response from Lp channels, and experiments with this level of depolarization were not pursued further. In fact, $-40 \mathrm{mV}$ voltage pulses $(10 \mathrm{mV}$ more positive than the calculated average depolarization) were necessary to produce responses that were comparable with those elicited by the 25 and $50 \mathrm{~Hz}$ trains. The $100 \mathrm{~Hz}$ train also elicited a larger response than would be expected from its calculated depolarization of $-41 \mathrm{mV}$. When compared with the average response seen to the $-40 \mathrm{mV}$ pulse $\left(p_{\mathrm{o}}=0.005 \pm 0.003\right)$, the average response to the $100 \mathrm{~Hz}$ train was significantly greater $\left(p_{\mathrm{o}}=0.03 \pm 0.008 ; p<0.01\right)$ and was actually more similar to that of the $-30 \mathrm{mV}$ pulse $\left(p_{\mathrm{o}}=\right.$ $0.025 \pm 0.005 ; p>0.6)$. These data suggest that action potential trains evoke larger responses of $\mathrm{Lp}$ channels than would be expected from the average depolarization of the stimulus. Thus, even the brief depolarization of the action potential may be sufficient to enhance Lp repolarization reopenings. An important caveat, however, is that the pipette voltage is not likely to follow the command voltage exactly. Therefore, the increased reopening activity may also result from a larger actual depolarization than that predicted from the stimulus waveform.

As described in Materials and Methods, use of an L-type channel agonist was essential for most of these studies. Therefore, it was important to determine whether the results obtained from these recordings would generalize to agonist-free conditions. This issue was addressed by making recordings in the absence of agonist and testing the same set of stimuli described previously. Only Lp channels were studied because the activity of these channels could be isolated by measuring the brief reopenings still observed without agonist (Fig. 1). However, the brevity of the openings made determination of channel number difficult and precluded accurate measurement of absolute $p_{\mathrm{o}}$. Therefore, the data were normalized.
In general, Lp channels studied under agonist-free conditions showed the same pattern of responses as those obtained in the presence of agonist. Channel reopenings could be observed during the repolarization period (Fig. $5 A$ ), and action potential trains of increasing frequency produced responses with higher $p_{\mathrm{o}}$ (Fig. $5 B)$. The same was true for square pulses of increasing amplitude. As seen with recordings done in the presence of agonist, square pulses to voltages more depolarized than $-30 \mathrm{mV}$ elicited responses greater than that produced by the $100 \mathrm{~Hz}$ train. Comparison of the responses in agonist (Fig. 4) and without agonist (Fig. 5) shows very similar profiles with unchanged frequency and voltage dependence. The response to the $25 \mathrm{~Hz}$ train was significantly less than that to the $100 \mathrm{~Hz}$ train $(p<0.05)$, and the response to the $-40 \mathrm{mV}$ pulse was significantly lower than the response to the $-20 \mathrm{mV}$ pulse $(p<0.01)$. This argues for the idea that the agonist did not change the general response characteristics of L channels although it had a clear effect on their magnitude.

This conclusion was supported further by experiments in which response properties before and after agonist exposure were studied in single recordings. The most complete experiment of this type is shown in Figure 6, in which all the stimuli tested were applied in a single recording both before and after addition of agonist. The pattern of responses from this single recording was the same as that observed previously. As expected, the magnitude of the reopening probability was much lower before addition of agonist (Fig. 6A) than after (Fig. 6B). Most important, however, was the near identity of the response profile before and after addition of agonist (Fig. 6C,D). Thus, it is reasonable to expect that addition of agonist does not alter the fundamental way in which $\mathrm{Lp}$ channels respond to action potential trains.

Having established that $\mathrm{Lp}$ channels can be activated by trains of action potentials, we wanted to assess specifically tetanic stimuli known to elicit changes in synaptic strength. Therefore we switched from relatively short action potential trains to longer ones. These were $200 \mathrm{~Hz}$ for $500 \mathrm{msec}$ and $100 \mathrm{~Hz}$ for $1 \mathrm{sec}$. These two stimuli are used to elicit NMDA receptor-independent LTP (Grover and Teyler, 1990) and NMDA receptor-dependent LTP, respectively. For comparison, we also examined Ls and Lp channel responses to $25 \mathrm{~Hz}$ for $1 \mathrm{sec}$ and a square pulse to $-30 \mathrm{mV}$ for $1 \mathrm{sec}$.

Initial experiments focused on repolarization reopenings and tail currents. As seen with the trains of $320 \mathrm{msec}$ duration, Lp 
Figure 3. Differential responses of Lp and Ls channels to action potential trains. A, Example traces of a cellattached recording from a multichannel patch that contained two $\mathrm{Lp}$ channels are shown. Only activity during the repolarization period (dashed line) was analyzed. In response to a $320 \mathrm{msec}, 100$ $\mathrm{Hz}$ train, the Lp channel exhibited numerous reopenings. Bottom trace, An ensemble average was constructed from 42 sweeps. $B$, A $320 \mathrm{msec}$ square pulse to $-30 \mathrm{mV}$ elicited repolarization activity comparable with that produced by the $100 \mathrm{~Hz}$ stimulus. Bottom trace, An ensemble average was constructed from 49 sweeps. The same patch shown in $A$ was used. $C$, Example traces of a cellattached recording containing two Ls channels are shown. The $100 \mathrm{~Hz}$ stimulus elicited an occasional tail current. Bottom trace, An ensemble average was constructed from 40 sweeps. D, A 320 msec square pulse to $-30 \mathrm{mV}$ elicited essentially no repolarization activity. Bottom trace, An ensemble average was constructed from 51 sweeps. The same patch shown in $C$ was used. In this and all subsequent figures, average currents have been divided by the number of channels in the patch.
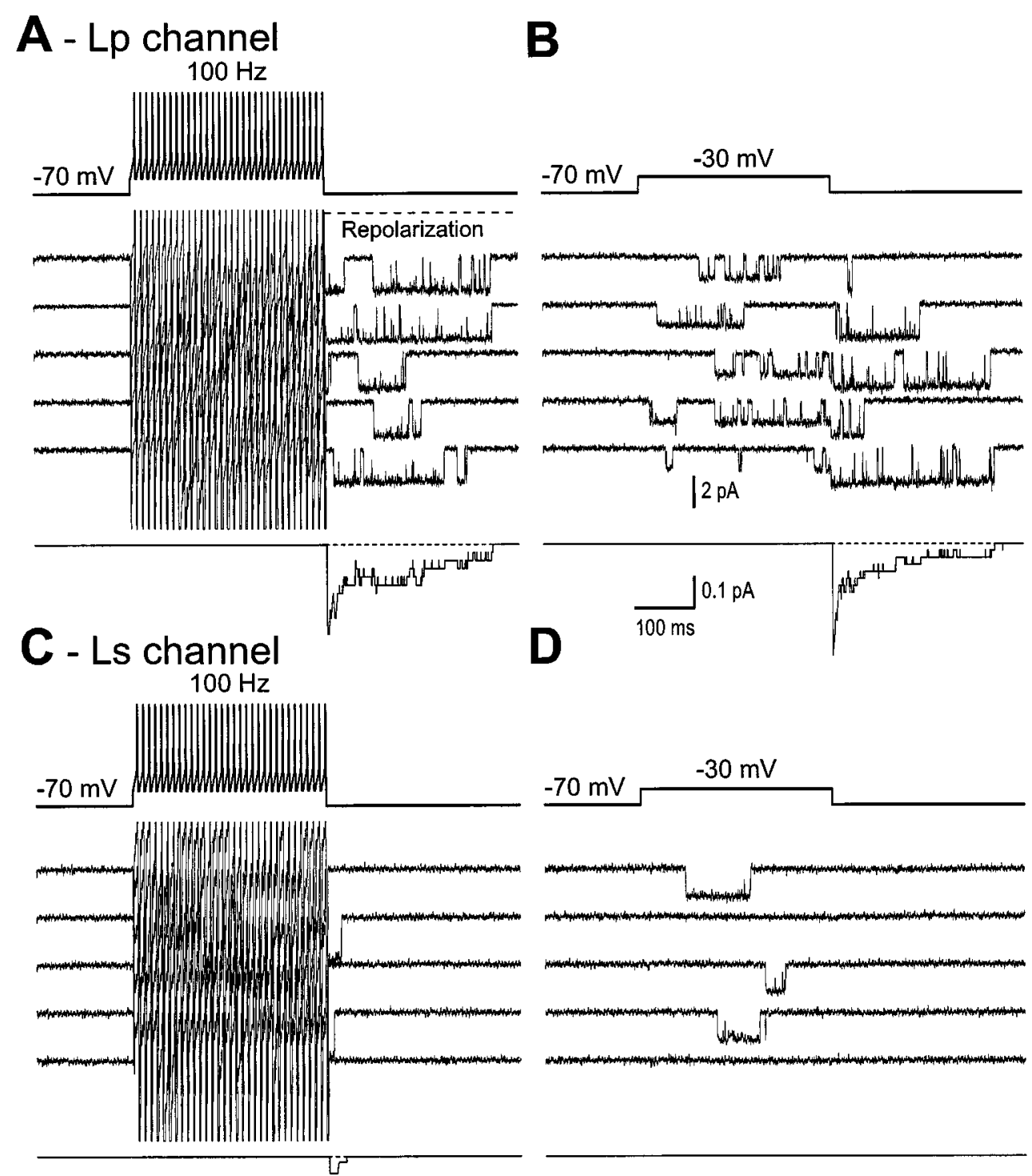

channels showed substantially greater responses to the $500 \mathrm{msec}$ and $1 \mathrm{sec}$ trains than did Ls channels (Fig. 7). The $500 \mathrm{msec}$ trains also provided a prolonged observation time during the repolarization period. With these stimuli, we noted that Lp channel reopenings could persist for as long as $700 \mathrm{msec}$ after the end of the action potential train (Fig. $7 A$ ). Comparison of $\mathrm{Lp}$ channel responses to the $100 \mathrm{~Hz}, 1 \mathrm{sec}$ train and the $200 \mathrm{~Hz}, 500 \mathrm{msec}$ train showed that the two stimuli did not produce statistically different levels of activity, although both of these stimuli evoked substantially greater responses than did the $1 \mathrm{sec}$ depolarization to $-30 \mathrm{mV}(p<0.01)$. Ls channel tail currents showed a similar response profile with the greatest responses to the 100 and $200 \mathrm{~Hz}$ stimuli (Fig. $7 B$ ). The Lp channel reopening $p_{\mathrm{o}}$ was, however, much greater in magnitude than was that observed for Ls channel tail currents $(p<0.01$ for all except $-30 \mathrm{mV}$ at $p<0.05)$.

For three of the stimuli tested (square pulse to $-30 \mathrm{mV}$ and 100 and $25 \mathrm{~Hz}$ trains) we were able to assess the effect of stimulus duration on Lp channel responses (comparison of data shown in Figs. 4, 7). For the $-30 \mathrm{mV}$ voltage pulse, the difference in response magnitude between the short $(320 \mathrm{msec})$ pulse and the long $(1 \mathrm{sec})$ pulse was not significant $(p>0.2)$. Increased duration of the action potential trains did produce larger responses, however. The $1 \mathrm{sec}, 25 \mathrm{~Hz}$ train elicited a 10-fold greater response than did the $320 \mathrm{msec}$ train $(p<0.01)$. The $1 \mathrm{sec}, 100 \mathrm{~Hz}$ train elicited a 2-fold greater response than did the $320 \mathrm{msec}$ train $(p<$ $0.05)$.

The trains of action potentials used in this part of the study resemble most closely the voltage change that an Lp or Ls channel would experience if it were located presynaptically. Action potential train stimuli may also be a useful model of voltage changes that a postsynaptic channel would experience as a result of back-propagating action potentials that invade a dendrite. The transfer characteristics of a synapse, however, are also a major determinant of a postsynaptic response. Recordings from CA1 neurons have shown that tetanic stimulation produces compound synaptic potentials and a transient burst of action potentials. To model a postsynaptic response, we simulated recordings made by others of the postsynaptic recording seen in response to a highfrequency train of action potentials (Grover and Teyler, 1990; Kapur et al., 1998). This response is comprised of an initial burst of action potentials followed by a maintained plateau potential. Our "burst-plateau" stimulus was made up of a $150 \mathrm{msec}$ train of action potentials at $100 \mathrm{~Hz}$ followed by an $850 \mathrm{msec}$ depolarization to $-30 \mathrm{mV}$. As with the previous stimuli, the holding poten- 


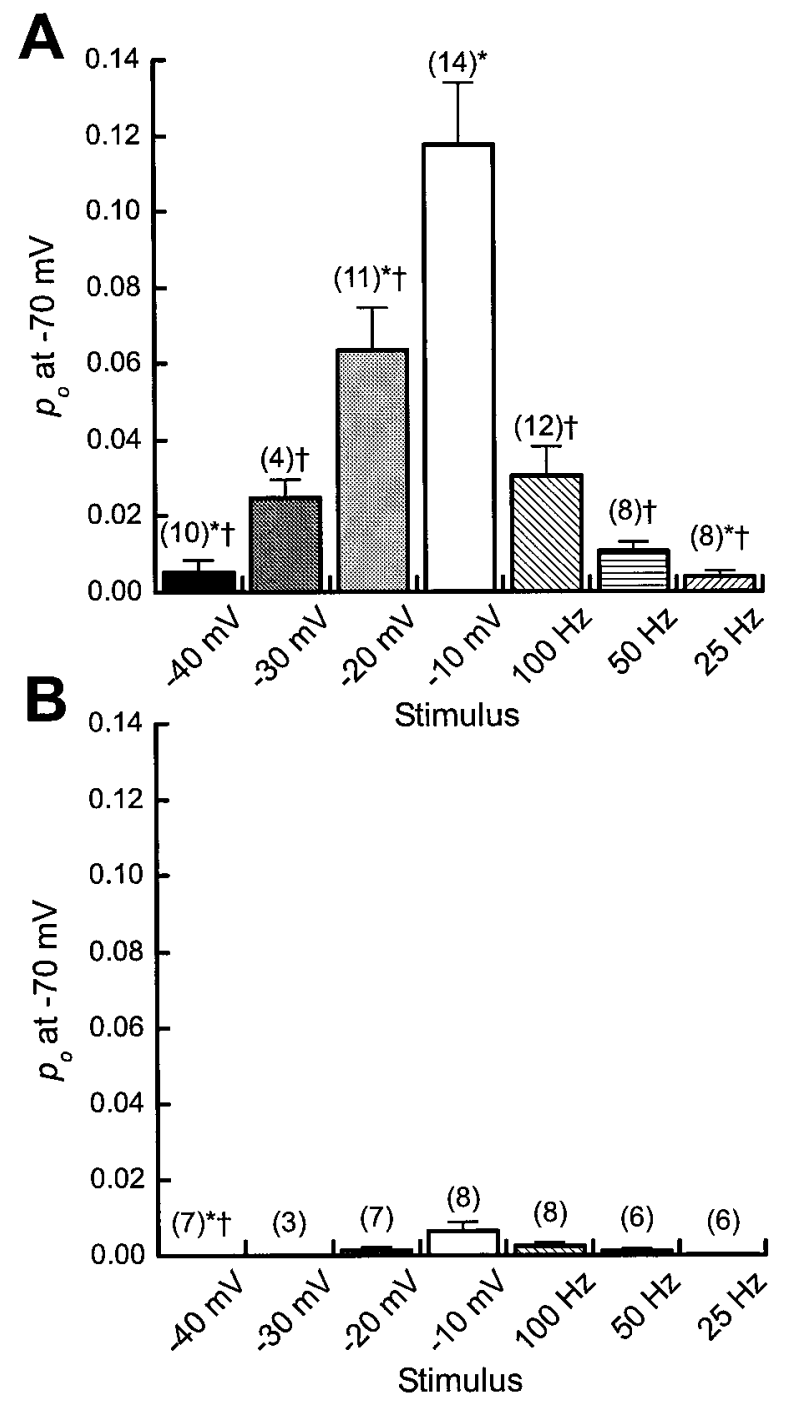

Figure 4. Action potential trains elicited larger repolarization activity of Lp channels than of Ls channels. A, Quantitative analysis of Lp channel reopenings in response to three different frequencies of action potential trains and four different square pulse depolarizations. Square pulses to $-10 \mathrm{mV}$ elicited the greatest level of $\mathrm{Lp}$ channel reopenings. Reopening

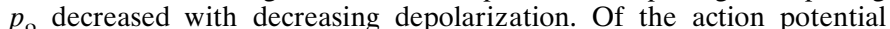
trains, the $100 \mathrm{~Hz}$ stimulus produced the greatest response, with reopening $p_{\mathrm{o}}$ decreasing with decreasing frequency. The number of recordings is indicated above each bar in parentheses. Responses statistically different from the response to the $100 \mathrm{~Hz}$ train are indicated by an $*(p<0.05)$. Responses statistically different from the response to $-10 \mathrm{mV}$ are indicated by a $\dagger(p<0.01$; one exception, $p<0.05$ for $-20 \mathrm{mV})$. $B$, Repolarization activity of Ls channels in response to the same stimuli used in $A$. For comparison, the scale of the $y$-axis is the same as that in $A$. None of the stimuli that produced Ls channel responses showed a significantly different magnitude from that of the $100 \mathrm{~Hz}$ stimulus or the -10 $\mathrm{mV}$ voltage pulse. The magnitude of the $\mathrm{Lp}$ channel responses was significantly greater than that of the Ls channels for the $-30 \mathrm{mV},-20$ $\mathrm{mV},-10 \mathrm{mV}, 100 \mathrm{~Hz}$, and $50 \mathrm{~Hz}$ stimuli $(p<0.01)$.

tial was $-70 \mathrm{mV}$. In addition to approximating the voltage changes seen by postsynaptic Lp and Ls channels in response to tetanic stimulation, this stimulus had the additional advantage of allowing us to observe channel activity during the stimulus itself, rather than only looking at responses during the repolarization period. Thus we quantified the responses during the $-30 \mathrm{mV}$ plateau portion of the stimulus. To assess the contribution of the
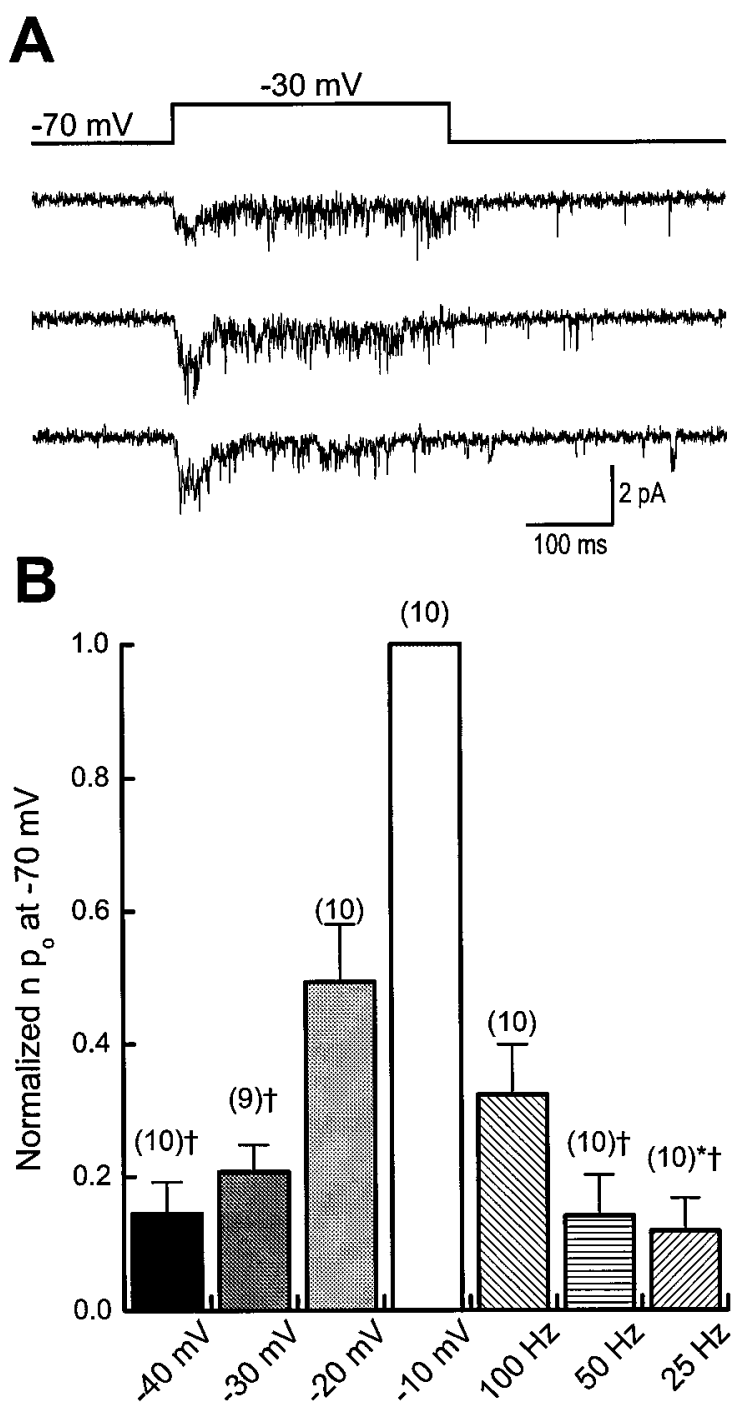

Stimulus

Figure 5. The pattern of $\mathrm{Lp}$ channel responses to action potential and square pulse stimuli is not changed in the absence of agonist. An analysis of repolarization responses obtained from Lp channels in the absence of FPL 64176 is shown. $A$, Example traces from a cell-attached multichannel recording showing that $\mathrm{Lp}$ channel reopenings can persist for several hundred milliseconds in the absence of agonist. B. Average responses normalized according to the activity elicited by the $-10 \mathrm{mV}$ square pulse. Note that the relative magnitudes of individual responses are essentially identical to those obtained in the presence of agonist. A response statistically different from the response to the $100 \mathrm{~Hz}$ train is indicated by an $*(p<0.05)$. Responses statistically different from the response to -20 $\mathrm{mV}$ are indicated by a $\dagger(p<0.01$; one exception, $p<0.05$ for $-30 \mathrm{mV})$.

initial burst of action potentials to the overall channel response, we also used a stimulus that was a simple $1 \mathrm{sec}$ square pulse to $-30 \mathrm{mV}$.

L p channels responded strongly to the burst-plateau stimulus, whereas Ls channels did not (Fig. 8A,C). Lp openings began during the burst of action potentials and continued throughout the plateau portion of the stimulus. This was seen clearly both in individual sweeps as well as in an ensemble average current (Fig. $8 A$, top average current). Ls channels also began opening during the train of action potentials, but opening frequency declined rapidly during the plateau at $-30 \mathrm{mV}$ (Fig. $8 C$ ). This was most 
A - Before agonist

Figure 6. Addition of agonist during a recording changes the magnitude but not the pattern of responses to stimuli. $A, \mathrm{Ex}-$ ample traces of a cell-attached multichannel recording from a patch that contained Ls channels and three to four Lp channels. Responses to a $-30 \mathrm{mV}$ square pulse are shown, with reopenings present in all three traces. $B$, Example traces obtained from the same patch shown in $A$ after addition of $1 \mu \mathrm{M}$ FPL 64176 . Reopenings were prolonged by the addition of agonist. $C$, Quantitative analysis of the agonistfree portion of the recording. As shown with the group data in Figures 4 and 5, the square pulse to $-10 \mathrm{mV}$ elicited the greatest response, with action potential trains producing smaller responses comparable with smaller depolarizations. $D$, Analysis of the recording after addition of agonist. The magnitude of the responses increased, but the pattern remained the same.

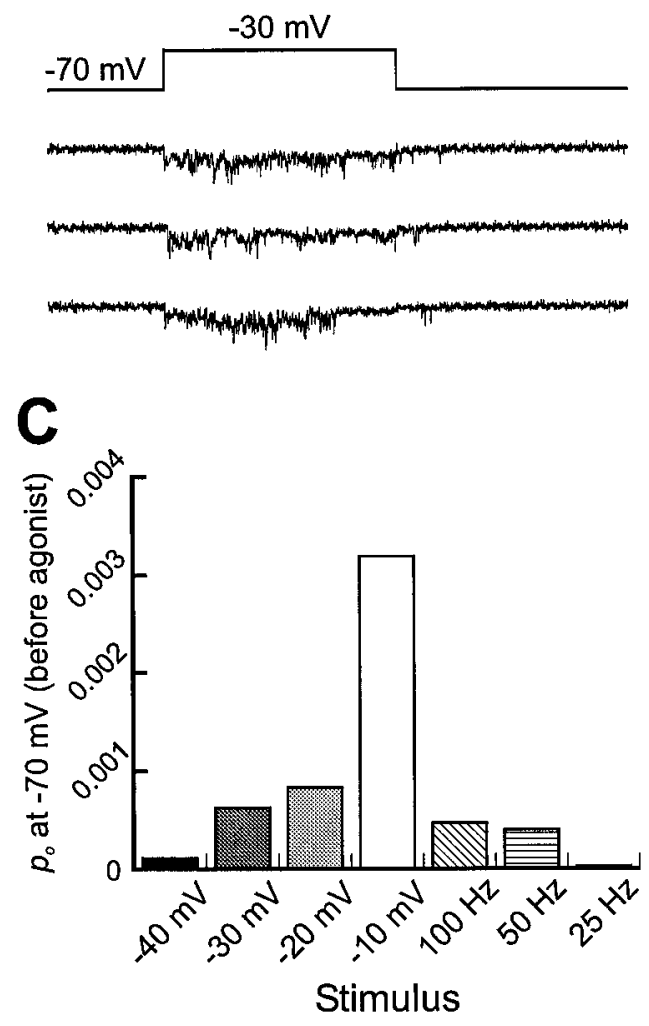

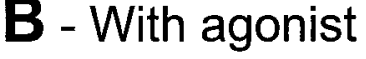
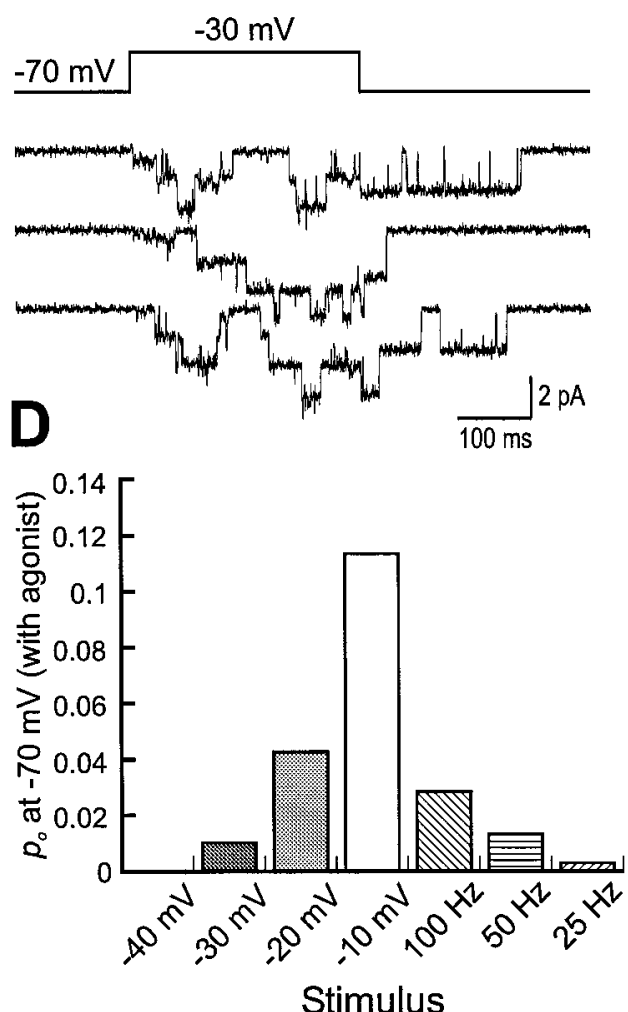

apparent in the ensemble average current in which an initial inward current was present that declined to a negligible amount after the action potential burst had ended even though the voltage remained at $-30 \mathrm{mV}$ (Fig. $8 C$, top average current). Comparison of the Lp and Ls average currents showed that although the two began with similar peak levels, the slow decay of L p current would provide greater total calcium influx than would the rapidly decaying Ls current.

To determine the contribution of the initial burst of action potentials to the production of the overall responses, we compared activity elicited by burst-plateau stimuli with that evoked by square pulses to the plateau voltage. In the absence of the initial burst of action potentials, Lp channel activity increased gradually (Fig. $8 B$ ), although it eventually reached the same magnitude that was seen with burst-plateau stimulation (Fig. $8 A$ ). Thus the burst of action potentials was responsible for the initial increase in Lp channel current.

Unlike Lp channels, the initial burst of action potentials was almost entirely responsible for the Ls channel responses to burstplateau stimuli. When the square pulse stimulus was used, the Ls channel average current was small (Fig. 8D), especially when compared with the Lp channel average current (Fig. $8 B$ ). The initial increase in current seen with burst-plateau stimulation was entirely absent.

One consequence of using the L-type channel agonist to identify Lp and Ls channels is the prolongation of channel open times. Although the comparison of agonist-containing and agonist-free recordings (Fig. 5) demonstrated that the overall pattern of channel activation did not depend on the presence of agonist, the shape of the ensemble average currents would be altered by the presence of long-duration tail currents, particularly for Ls channels. To assess the contribution of prolonged tail currents, the ensemble average responses of Ls and L p channels were constructed separately with and without the addition of tail currents (Fig. 8A-D, bottom traces). The average currents with and without tail openings were only slightly different for $\mathrm{Lp}$ channels. This is consistent with the general gating behavior of L p channels because activity during the repolarization period arises predominantly from reopenings and not tail currents. The Ls channel average currents, however, were more affected by the removal of tail currents. The response to the initial burst of action potentials was much smaller. This again was a straightforward prediction from Ls channel responses in which tail currents are exclusively responsible for repolarization period activity and, in this case, plateau period activity.

To compare Lp and Ls channel responses to the burst-plateau stimuli quantitatively, we measured open probability at the plateau voltage of $-30 \mathrm{mV}$ and compared this with channel open probability seen in response to the square pulse to $-30 \mathrm{mV}$ (Fig. $9 A$ ). This analysis substantiated two points. First, Lp channels responded much more robustly during the entire stimulus than did Ls channels ( $p<0.01$ for both types of stimuli). Second, a $-30 \mathrm{mV}$ depolarization was more effective at activating $\mathrm{Lp}$ channels when it was preceded by a short burst of action potentials at $100 \mathrm{~Hz}(p<0.05)$. Ls channels, however, responded similarly to a voltage of $-30 \mathrm{mV}$ regardless of whether it was preceded by the initial burst of action potentials $(p>0.2)$. If anything, there was a slight tendency for Ls channels to respond less well to a $-30 \mathrm{mV}$ depolarization when it was preceded by action potentials (Fig. 9A).

To gain a better understanding of the mechanism by which the burst of action potentials increased the $\mathrm{Lp}$ channel response to 

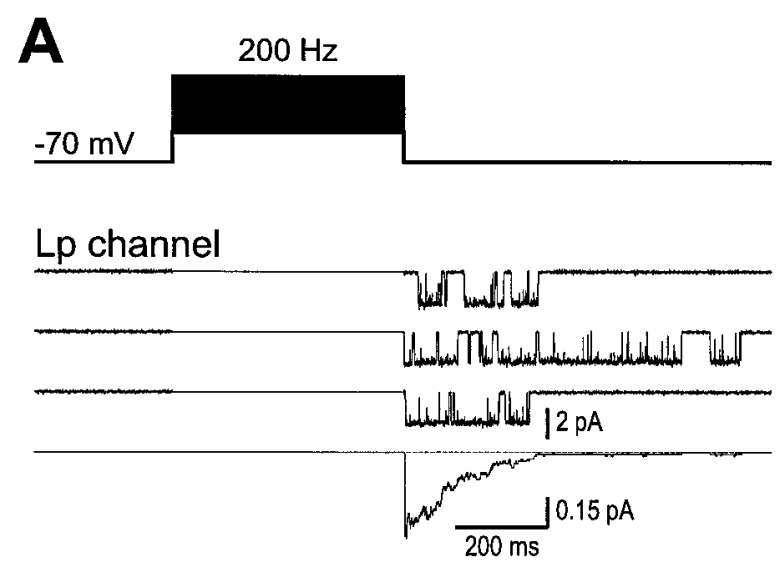

\section{Ls channel}
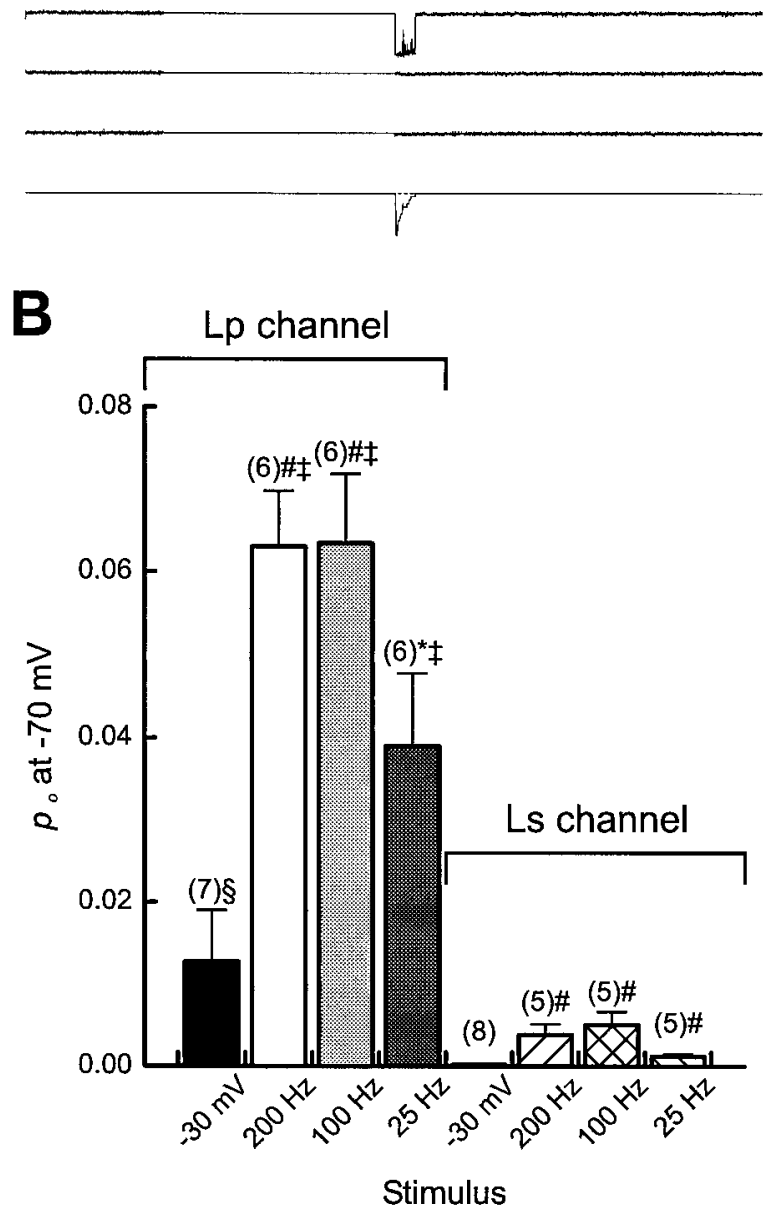

Figure 7. Stimuli that mimic those used to induce synaptic plasticity elicit different responses in $\mathrm{Lp}$ and $\mathrm{Ls}$ channels. A, Example traces of a cell-attached multichannel recording from a patch that contained two Lp channels (top) and a patch containing four Ls channels (bottom). A 500 msec, $200 \mathrm{~Hz}$ stimulus elicited Lp channel reopenings and Ls channel tail currents. Activity during the action potential train was completely obscured by the stimulus artifact and was blanked out in the traces shown. Bottom traces, For both $\mathrm{Lp}$ and Ls recordings, an ensemble average constructed from 105 and 38 sweeps, respectively. B. Summary Lp and Ls channel repolarization responses to four different stimuli: a $1 \mathrm{sec}$, $-30 \mathrm{mV}$ square pulse; a $500 \mathrm{msec}, 200 \mathrm{~Hz}$ train of action potentials; a 1 sec, $100 \mathrm{~Hz}$ train of action potentials; and a $1 \mathrm{sec}, 25 \mathrm{~Hz}$ train of action potentials. The three action potential train stimuli produced significantly larger Lp and Ls channel responses than did the square pulse $\left({ }^{*} p<0.05\right.$; $\# p<0.01)$. All L $p$ channel responses were also significantly greater than were the Ls responses to the same stimuli $(\$ p<0.05 ; \ddagger p<0.01)$. the $-30 \mathrm{mV}$ plateau voltage, we quantified the number of openings and the percentage of null sweeps $\left(p_{\text {null }}\right)$ for Lp channels (Fig. 9B,C). There was not a significant difference in these two parameters between the two stimulus conditions $(p>0.1)$. There was, however, a tendency for stimuli with action potentials to elicit more L $\mathrm{p}$ channel openings during the plateau voltage and to produce fewer null sweeps than produced by stimuli without action potentials. Thus the effect of the action potential burst on Lp channel open probability could not be definitively attributed to an increase in the number of openings or a change in availability.

In the absence of a clear effect of the initial action potential burst on channel-opening frequency or availability, we also examined the possibility that the increase in current seen with burstplateau stimuli could be attributed to an increase in channel open time (Fig. 9D). With action potential bursts, the extracted mean open times at $-30 \mathrm{mV}$ for $\mathrm{Lp}$ channels were $0.8,7.2$, and 19.4 msec with relative proportions of $0.08,0.38$, and 0.53 , respectively. With the $-30 \mathrm{mV}$ step pulse alone, the open times were $0.9,9.9$, and $22.9 \mathrm{msec}$ with relative proportions of $0.33,0.36$, and 0.3 , respectively. Thus the inclusion of the $150 \mathrm{msec}$ train of action potentials before the $-30 \mathrm{mV}$ depolarization causes a significant shift in the observed frequency of long openings versus short ones (Kolmogorov-Smirnov two-sample test, $p<0.01$ ). The mean open times themselves, however, were not different. Taken together, these data suggest that the $150 \mathrm{msec}$ burst of action potentials substantially enhanced the entire response to the $850 \mathrm{msec}$ plateau voltage by causing a shift to a longer-opening state coupled with a potential increase in the number of openings.

\section{DISCUSSION}

In this study, we have examined the effects of action potential burst stimuli on the activity of the Lp and Ls subtypes of L-type calcium channels. The rationale was to study physiologically relevant stimuli of the type traditionally used to elicit changes in synaptic strength. Action potential trains of different frequency and duration were tested for their ability to elicit openings and reopenings of the two channel types. All of the stimuli evoked openings of both channel types during the action potential train itself. Detailed measurement of activity during repolarization revealed that trains of action potentials elicited bouts of $\mathrm{Lp}$ channel reopenings that increased with increasing frequency. Ls channel tail currents were also seen, but at a dramatically lower level than was seen with L p channel reopenings. Trains of longer duration but with the same frequency also evoked greater Lp channel reopenings and increased the frequency with which Ls channel tail currents were seen. None of the stimuli tested, however, induced reopening of Ls channels as identified by their characteristic long opening in the presence of agonist. Therefore, trains of action potentials effectively activated both Ls and Lp channels but produced more sustained Lp channel activity, whereas Ls channel activity ended after the action potential train ended. Thus, Lp channel activity remained elevated when the driving force on calcium ions was the highest.

Trains of individual action potentials of the type described above can be related easily to presynaptic activity during tetanic stimulation. There is, however, good reason to expect that L $\mathrm{p}$ and Ls channels are more likely to be localized to proximal dendrites and somata than to axonal terminals (Jones et al., 1989; Westenbroek et al., 1990; Hell et al., 1993; Luebke et al., 1993; Magee and Johnston, 1995; Kavalali et al., 1997b; Kapur et al., 1998). Lp and Ls channels could conceivably experience action potential 
Figure 8. Stimuli that mimic postsynaptic responses to high-frequency stimulation strongly activate Lp channels. $A$, Example traces and two ensemble average currents of a cellattached recording from a patch that contained two Lp channels. The stimulus used was a brief burst of action potentials riding on top of a maintained plateau potential. Because of the small number of channels in the patch, partial leak subtraction of activity during the action potential burst was possible. Lp channel activity began during the action potential burst, was maintained throughout the plateau potential, and continued during the repolarization period. This was evident in the individual traces as well as in the average currents. The top (Tail current included) and bottom (Tail current excluded) average currents were constructed from 240 sweeps. The top average current was a nonconditional average that contained all sweeps. The bottom average current had all tail currents removed. Sweeps that consisted solely of tail currents were counted as nulls, and sweeps that contained both tail currents and reopenings had the tail currents removed. Exclusion of the tail currents from the plateau and repolarization average currents did not have a significant impact on the time course of the Lp channel current. $B$, Example traces from the same patch shown in $A$ but in response to square pulse depolarization to $-30 \mathrm{mV}$. $\mathrm{Lp}$ channels showed slow activation and maintained current throughout the depolarization that continued into the repolarization period. The top and bottom average currents were constructed as described in $A$ from 214 sweeps. $C$, Cell-attached recording from a patch containing Ls channels. The channel was activated strongly during the action potential burst but declined rapidly during the plateau portion of the stimulus and ceased after repolarization. The top and bottom average currents were constructed as described in $A$ from 253 sweeps. Exclusion of the tail currents eliminated the bulk of Ls channel current during the plateau depolarization. $D$, Same patch shown in $C$ but traces shown were responses to a square pulse depolarization to $-30 \mathrm{mV}$. Activity was low throughout the stimulus. The top and bottom average currents were constructed from 222 sweeps.

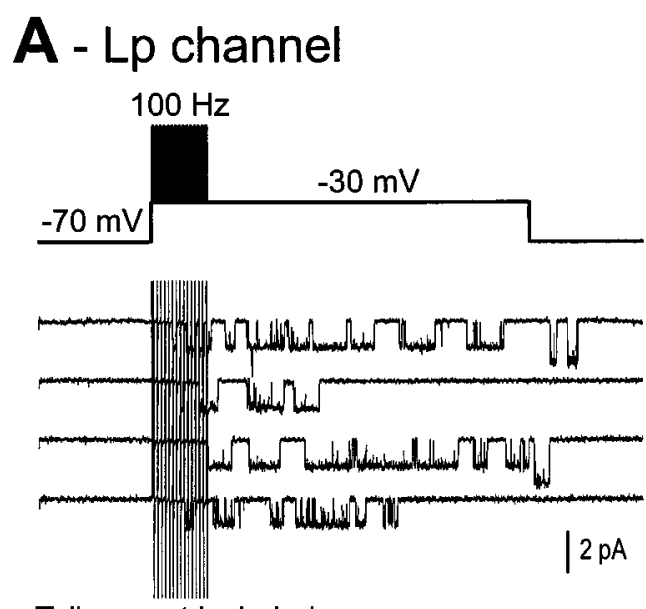

Tail current included

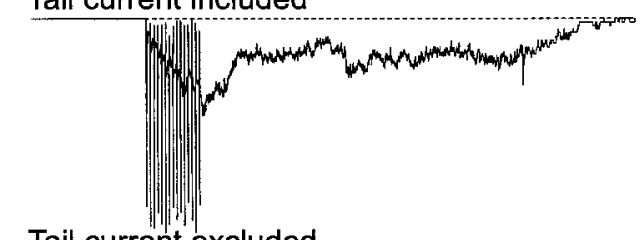

Tail current excluded

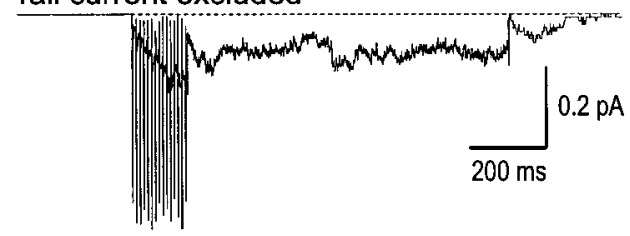

Tail current excluded

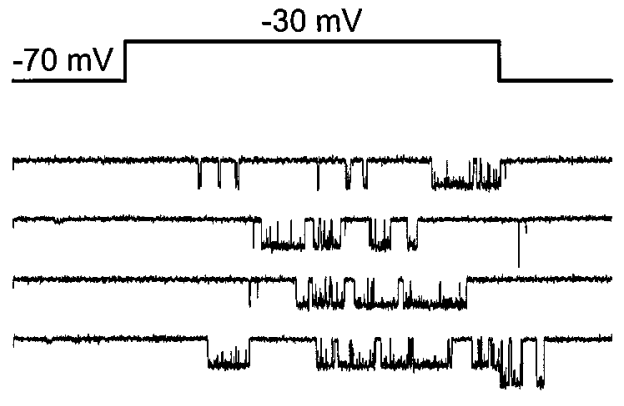

Tail current included
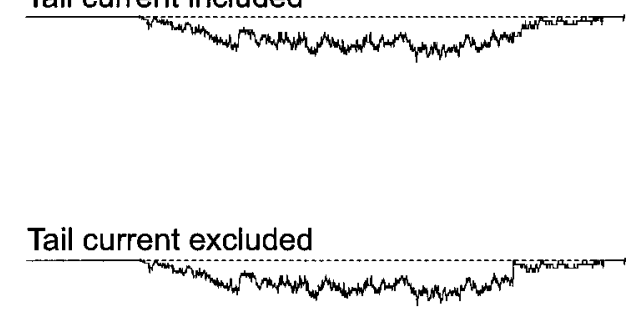

\section{C - Ls channel}
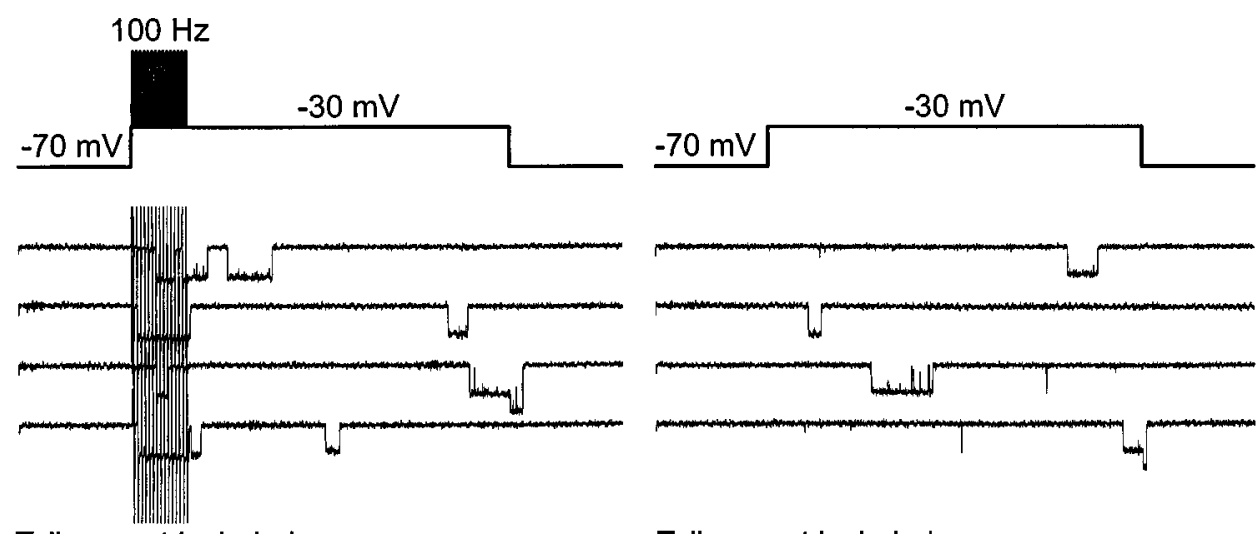

Tail current included
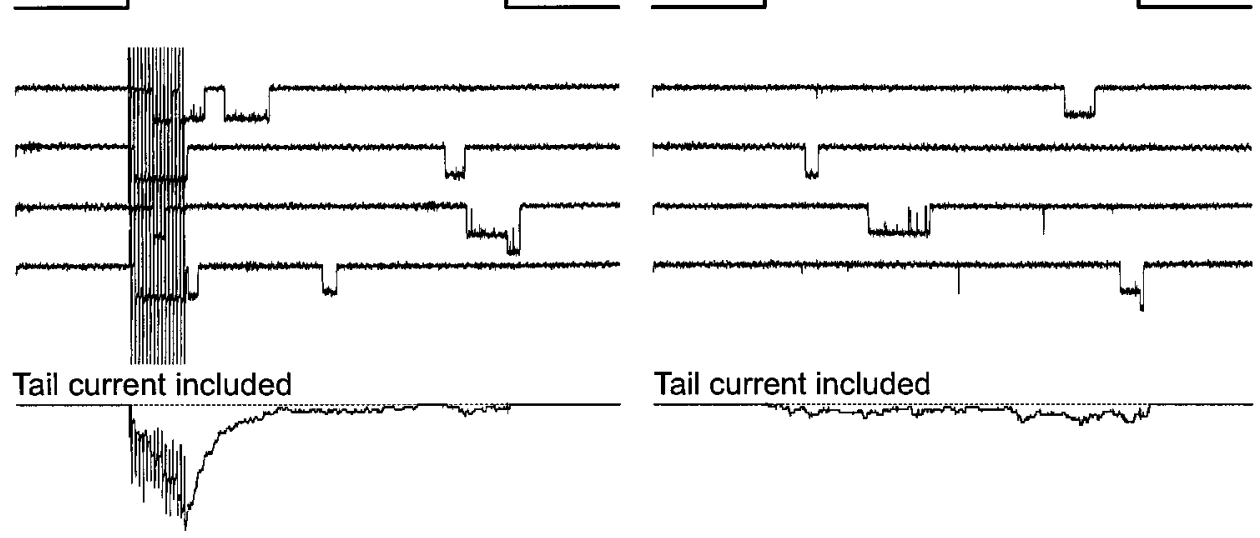

Tail current included

Tail current excluded

Tail current excluded trains as a result of active back-propagation into a dendrite (for review, see Stuart et al., 1997), especially under conditions that reduce decrement during the train (Colbert et al., 1997; Tsubokawa and Ross, 1997). Trains of somatically induced action potentials have been shown to produce dramatic increases in intracellular calcium (Jaffe et al., 1992), which are consistent with the properties of $\mathrm{Lp}$ channels described here.

A second way in which we examined voltage changes experi- 

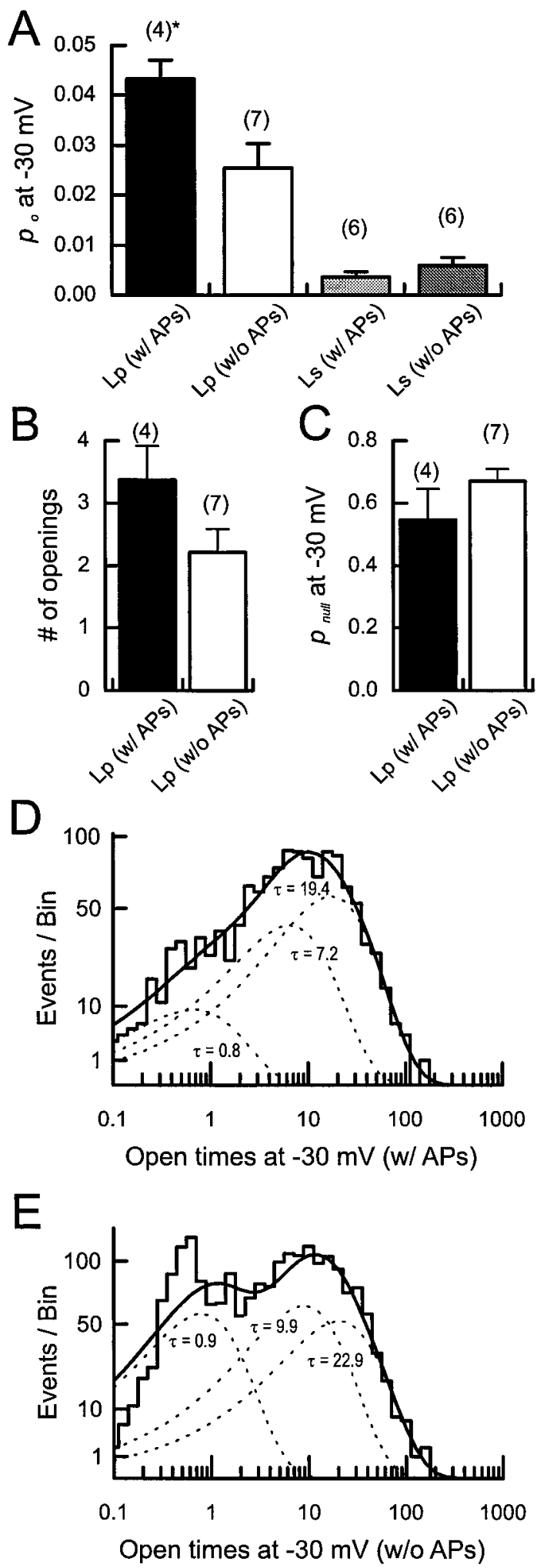

Figure 9. Action potential bursts enhance Lp channel activity during plateau depolarizations. $A$, Quantification of open probability during the plateau portion of the stimuli shown in Figure $8, A$ and $B$, is presented. $\mathrm{Lp}$ channel open probability during the plateau portion of the stimulus was significantly greater when preceded by a burst of action potentials. Ls channel open probability was not different between the two conditions. Lp channel $p_{\mathrm{o}}$ was significantly greater than Ls channel $p_{\mathrm{o}}$ for both conditions $(p<0.05)$. $B$, The number of $\mathrm{Lp}$ channel openings during the plateau depolarization was somewhat larger, but was not significantly greater, for enced by postsynaptic Lp channels was by simulating postsynaptic responses to a burst of presynaptic action potentials. Stimuli modeled after published postsynaptic recordings of neuronal activity during stimulus trains consisted of an initial burst of action potentials followed by a plateau voltage that was sustained for the duration of the action potential firing. This stimulus elicited strong activation of L $\mathrm{p}$ channels but relatively modest activity in Ls channels. Particularly evident was the difference in open probability during the plateau portion of the stimulus. Ls channels were virtually silent, whereas Lp channels showed openings that continued for the duration of the stimulus. In addition, Lp channels also showed reopenings after cessation of the stimulus. Therefore, the overall activation of L p channels was substantially greater than that of Ls channels for a stimulus designed to simulate a postsynaptic response to a high-frequency train of presynaptic action potentials.

Comparison of responses to burst-plateau stimuli and to step depolarizations to the plateau voltage revealed that the initial burst of action potentials significantly augmented the activity of L p channels. The increase in open probability could be attributed to a shift from short- to longer-duration openings. A similar phenomenon has been reported for anomalous L-type channels in spinal motor neurons (Hivert et al., 1999). In those studies, depolarizations of increasing voltage or duration increased the probability of observing long with respect to short reopenings. Functionally, this increases the responsiveness of L p channels to physiologically relevant stimuli in which a steady depolarization is preceded by an initial burst of action potentials.

The results of this study suggest that of the known DHPsensitive calcium channels, the one more likely to participate in the induction of the NMDA receptor-independent LTP would be the Lp channel. This conclusion is based on a recent study showing that NMDA receptor-independent LTP is induced postsynaptically (Yeckel et al., 1999), meaning that our stimulus that simulates a postsynaptic response to tetanic stimulation provides the most meaningf ul comparison between Ls and Lp channels. For that stimulus, Lp channels showed much larger and long-lasting activity than did Ls channels, thus providing a far more substantial calcium influx. Our comparisons of agonistcontaining and agonist-free conditions suggest that although the absolute levels of activity would likely be smaller under physiological conditions, the relative contributions of $\mathrm{Lp}$ and Ls channels should remain unchanged.

It has been shown that calcium influx through dihydropyridinesensitive calcium channels can potentiate synaptic transmission in hippocampal neurons under a variety of conditions, including TEA-induced LTP (Huang and Malenka, 1993) and short-term potentiation induced by repeated postsynaptic depolarization (Kullmann et al., 1992). Although typically associated with the hippocampal mossy fiber-to-CA3 pyramidal neuron synapse, L-type channel-dependent LTP has also been found in the hippocampal CA3-to-CA1 pyramidal neuron synapse (Grover and

stimuli with the action potential burst. For an accurate comparison, an equal amount of time was analyzed for the two types of stimuli. $C$, Analysis of the null sweep probability for $\mathrm{Lp}$ channels did not show a significant difference for the stimuli with and without the action potential burst. $D, E$, Comparison of the open-state dwell time duration for $\mathrm{Lp}$ channels during the plateau depolarization is shown. The distributions for Lp opening resulting from stimuli with $(D)$ and without $(E)$ the initial burst of action potentials were significantly different (KolmogorovSmirnov two-sample test, $p<0.01$ ). 
Teyler, 1990) in which it is coexpressed with NMDA receptordependent LTP (Morgan and Teyler, 1999). An interesting feature of calcium channel-dependent LTP is its age dependence, particularly with regard to age-related learning disorders. It has been shown that systemic administration of nimodipine can reverse a performance decrement in aged animals on a conditioned eye-blink task (Deyo et al., 1989). This decrease in performance has been correlated with increased calcium current in hippocampal pyramidal neurons (Pitler and Landfield, 1990; Moyer and Disterhoft, 1994; Campbell et al., 1996) and has been specifically correlated with L-type calcium channel reopenings at hyperpolarized voltages (Thibault and Landfield, 1996). It has also been shown that the relative contribution of NMDA receptorindependent LTP increases with age in hippocampal CA1 neurons (Shankar et al., 1998) and that there is an age-dependent modulation of the induction of LTP and long-term depression (Coussens et al., 1997; Norris et al., 1998). If one assumes that these functions result from the activity of $\mathrm{Lp}$ channels, then a detailed understanding of this subtype becomes especially important to elucidating the basis of these age-related changes.

In addition to synaptic plasticity, there is considerable evidence of the involvement of L-type channels in electrophysiological phenomena such as motor neuron plateau potentials (for review, see Kiehn and Eken, 1998), afterhyperpolarizations (for review, see Sah, 1996), and opioid enhancement of intracellular calcium oscillations (Przewlocki et al., 1999). L-type channels have also been implicated in a variety of constitutive functions such as neuronal survival and differentiation (Shitaka et al., 1996; Brosenitsch et al., 1998) and regulation of gene transcription (for review, see Bito et al., 1997), especially with regard to cAMP response element-binding protein (CREB) phosphorylation (Murphy et al., 1991; Impey et al., 1996; Liu and Graybiel, 1996, 1998; Cigola et al., 1998; Shieh et al., 1998; Tao et al., 1998; Rajadhyaksha et al., 1999). There is, at present, no definitive proof for differential involvement of one L-type channel subtype over the other in these functions. It has been suggested, however, that L-type calcium channels can serve as a "kinetic filter" responsible for discriminating synaptic from action potential-mediated calcium influx (Mermelstein et al., 2000), a finding that provides a mechanistic basis for previous work showing that synaptic activity is much more effective than action potential firing at causing rapid, calcium-dependent phosphorylation of CREB (Deisseroth et al., 1996). One critical feature of the L-type calcium current responsible for this phenomenon was low activation voltage - a key characteristic that distinguishes Lp channels from Ls channels. This difference is especially clear in Figure 8 in which a model postsynaptic response evokes far greater activity of $\mathrm{Lp}$ channels than of Ls channels. Thus it is conceivable that Lp channels may be used as a means for enhancing calcium entry in response to synaptic input.

The molecular nature of $\mathrm{Lp}$ channel gating is currently unknown. Reopenings have been observed under a variety of circumstances (Fisher et al., 1990; Forti and Pietrobon, 1993; Thibault et al., 1993; Kavalali and Plummer, 1994; Cloues et al., 1997) and attributed to factors such as recovery from inactivation (Slesinger and Lansman, 1991, 1996), entry and exit into a nonabsorbing closed state (Forti and Pietrobon, 1993; Hivert et al., 1999), and altered voltage dependence (Kavalali and Plummer, 1996). There is substantial evidence, however, that reopenings are not a uniform property of L-type channels and instead reflect activity of a functionally distinct subtype of channel (Kavalali et al., 1997a; Hivert et al., 1999). It is clear that there is sufficient diversity in L-type channel $\alpha$ subunits to support distinctive gating patterns (for review, see Randall and Benham, 1999). Several alternative splicing products have been identified (Snutch et al., 1991; Soldatov, 1994) that have been shown to vary in features such as sensitivity to dihydropyridine antagonists (Soldatov et al., 1995; Zuhlke et al., 1998). There is also diversity in the ancillary $\beta$ and $\alpha_{2} \delta$ subunit gene products and alternative splice products (Kim et al., 1992). A final determination awaits successful cloning and expression of calcium channel activity that reproduces the characteristics of $\mathrm{Lp}$ channel reopenings.

\section{REFERENCES}

Bito H, Deisseroth K, Tsien RW (1997) $\mathrm{Ca}^{2+}$-dependent regulation in neuronal gene expression. Curr Opin Neurobiol 7:419-429.

Bliss TV, Collingridge GL (1993) A synaptic model of memory: longterm potentiation in the hippocampus. Nature 361:31-39.

Brosenitsch TA, Salgado-Commissariat D, Kunze DL, Katz DM (1998) A role for L-type calcium channels in developmental regulation of transmitter phenotype in primary sensory neurons. J Neurosci 18:1047-1055.

Campbell LW, Hao SY, Thibault O, Blalock EM, Landfield PW (1996) Aging changes in voltage-gated calcium currents in hippocampal CA1 neurons. J Neurosci 16:6286-6295.

Cigola E, Volpe BT, Lee JW, Franzen L, Baker H (1998) Tyrosine hydroxylase expression in primary cultures of olfactory bulb: role of L-type calcium channels. J Neurosci 18:7638-7649.

Cloues RK, Tavalin SJ, Marrion NV (1997) $\exists$-Adrenergic stimulation selectively inhibits long-lasting L-type calcium channel facilitation in hippocampal pyramidal neurons. J Neurosci 17:6493-6503.

Colbert CM, Magee JC, Hoffman DA, Johnston D (1997) Slow recovery from inactivation of $\mathrm{Na}^{+}$channels underlies the activity-dependent attenuation of dendritic action potentials in hippocampal CA1 pyramidal neurons. J Neurosci 17:6512-6521.

Collingridge GL, Kehl SJ, McLennan H (1983) Excitatory amino acids in synaptic transmission in the Schaffer collateral-commissural pathway of the rat hippocampus. J Physiol (Lond) 334:33-46.

Colquhoun D, Sigworth FJ (1983) Fitting and statistical analysis of single-channel records. In: Single-channel recording (Sakmann B, Neher E, eds), pp 191-263. New York: Plenum.

Coussens CM, Kerr DS, Abraham WC (1997) Glucocorticoid receptor activation lowers the threshold for NMDA-receptor-dependent homosynaptic long-term depression in the hippocampus through activation of voltage-dependent calcium channels. J Neurophysiol 78:1-9.

Deisseroth K, Bito H, Tsien RW (1996) Signaling from synapse to nucleus: postsynaptic CREB phosphorylation during multiple forms of hippocampal synaptic plasticity. Neuron 16:89-101.

Deyo RA, Straube KT, Disterhoft JF (1989) Nimodipine facilitates associative learning in aging rabbits. Science 243:809-811.

Fisher RE, Gray R, Johnston D (1990) Properties and distribution of single voltage-gated calcium channels in adult hippocampal neurons. J Neurophysiol 64:91-104.

Forti L, Pietrobon D (1993) Functional diversity of L-type calcium channels in rat cerebellar neurons. Neuron 10:437-450.

Grover LM, Teyler TJ (1990) Two components of long-term potentiation induced by different patterns of afferent activation. Nature 347:477-479.

Hamill OP, Marty A, Neher E, Sakmann B, Sigworth FJ (1981) Improved patch-clamp techniques for high-resolution current recording from cells and cell-free membrane patches. Pflügers Arch 391:85-100.

Harris EW, Ganong AH, Cotman CW (1984) Long-term potentiation in the hippocampus involves activation of $N$-methyl-D-aspartate receptors. Brain Res 323:132-137.

Hell JW, Westenbroek RE, Warner C, Ahlijanian MK, Prystay W, Gilbert MM, Snutch TP, Catterall WA (1993) Identification and differential subcellular localization of the neuronal class C and class D L-type calcium channel alpha 1 subunits. J Cell Biol 123:949-962.

Hivert B, Luvisetto S, Navangione A, Tottene A, Pietrobon D (1999) Anomalous L-type calcium channels of rat spinal motoneurons. J Gen Physiol 113:679-694.

Huang YY, Malenka RC (1993) Examination of TEA-induced synaptic enhancement in area CA1 of the hippocampus: the role of voltagedependent $\mathrm{Ca}^{2+}$ channels in the induction of LTP. J Neurosci 13:568-576. 
Impey S, Mark M, Villacres EC, Poser S, Chavkin C, Storm DR (1996) Induction of CRE-mediated gene expression by stimuli that generate long-lasting LTP in area CA1 of the hippocampus. Neuron 16:973-982.

Jaffe DB, Johnston D, Lasser-Ross N, Lisman JE, Miyakawa H, Ross WN (1992) The spread of $\mathrm{Na}+$ spikes determines the pattern of dendritic $\mathrm{Ca}^{2+}$ entry into hippocampal neurons. Nature 357:244-246.

Johnston D, Williams S, Jaffe D, Gray R (1992) NMDA-receptorindependent long-term potentiation. Annu Rev Physiol 54:489-505.

Jones OT, Kunze DL, Angelides KJ (1989) Localization and mobility of omega-conotoxin-sensitive $\mathrm{Ca}^{2+}$ channels in hippocampal CA1 neurons. Science 244:1189-1193.

Kapur A, Yeckel MF, Gray R, Johnston D (1998) L-type calcium channels are required for one form of hippocampal mossy fiber LTP. J Neurophysiol 79:2181-2190.

Kavalali ET, Plummer MR (1994) Selective potentiation of a novel calcium channel in rat hippocampal neurones. J Physiol (Lond) 480:475-484.

Kavalali ET, Plummer MR (1996) Multiple voltage-dependent mechanisms potentiate calcium channel activity in hippocampal neurons. J Neurosci 16:1072-1082.

Kavalali ET, Hwang KS, Plummer MR (1997a) cAMP-dependent enhancement of dihydropyridine-sensitive calcium channel availability in hippocampal neurons. J Neurosci 17:5334-5348.

Kavalali ET, Zhuo M, Bito H, Tsien RW (1997b) Dendritic $\mathrm{Ca}^{2+}$ channels characterized by recordings from isolated hippocampal dendritic segments. Neuron 18:651-663.

Kiehn O, Eken T (1998) Functional role of plateau potentials in vertebrate motor neurons. Curr Opin Neurobiol 8:746-752.

Kim HL, Kim H, Lee P, King RG, Chin H (1992) Rat brain expresses an alternatively spliced form of the dihydropyridine-sensitive L-type calcium channel alpha 2 subunit. Proc Natl Acad Sci USA 89:3251-3255.

Kullmann DM, Perkel DJ, Manabe T, Nicoll RA (1992) $\mathrm{Ca}^{2+}$ entry via postsynaptic voltage-sensitive $\mathrm{Ca}^{2+}$ channels can transiently potentiate excitatory synaptic transmission in the hippocampus. Neuron 9:1175-1183.

Levine ES, Dreyfus CF, Black IB, Plummer MR (1995) Brain-derived neurotrophic factor rapidly enhances synaptic transmission in hippocampal neurons via postsynaptic tyrosine kinase receptors. Proc Natl Acad Sci USA 92:8074-8077.

Liu FC, Graybiel AM (1996) Spatiotemporal dynamics of CREB phosphorylation: transient versus sustained phosphorylation in the developing striatum. Neuron 17:1133-1144.

Liu FC, Graybiel AM (1998) Region-dependent dynamics of cAMP response element-binding protein phosphorylation in the basal ganglia. Proc Natl Acad Sci USA 95:4708-4713.

Luebke JI, Dunlap K, Turner TJ (1993) Multiple calcium channel types control glutamatergic synaptic transmission in the hippocampus. Neuron 11:895-902.

Magee JC, Johnston D (1995) Synaptic activation of voltage-gated channels in the dendrites of hippocampal pyramidal neurons. Science 268:301-304.

Malenka RC, Nicoll RA (1993) NMDA-receptor-dependent synaptic plasticity: multiple forms and mechanisms. Trends Neurosci 16:521-527.

Mermelstein PG, Bito H, Deisseroth K, Tsien RW (2000) Critical dependence of cAMP response element-binding protein phosphorylation on L-type calcium channels supports a selective response to EPSPs in preference to action potentials. J Neurosci 20:266-273.

Morgan SL, Teyler TJ (1999) VDCCs and NMDARs underlie two forms of LTP in CA1 hippocampus in vivo. J Neurophysiol 82:736-740.

Moyer Jr JR, Disterhoft JF (1994) Nimodipine decreases calcium action potentials in rabbit hippocampal CA1 neurons in an age-dependent and concentration-dependent manner. Hippocampus 4:11-17.

Murphy TH, Worley PF, Baraban JM (1991) L-type voltage-sensitive calcium channels mediate synaptic activation of immediate early genes. Neuron 7:625-635.

Norris CM, Halpain S, Foster TC (1998) Reversal of age-related alterations in synaptic plasticity by blockade of L-type $\mathrm{Ca}^{2+}$ channels. J Neurosci 18:3171-3179.

Pitler TA, Landfield PW (1990) Aging-related prolongation of calcium spike duration in rat hippocampal slice neurons. Brain Res 508:1-6.

Przewlocki R, Parsons KL, Sweeney DD, Trotter C, Netzeband JG, Siggins GR, Gruol DL (1999) Opioid enhancement of calcium oscil- lations and burst events involving NMDA receptors and L-type calcium channels in cultured hippocampal neurons. J Neurosci 19:9705-9715.

Rajadhyaksha A, Barczak A, Macias W, Leveque JC, Lewis SE, Konradi C (1999) L-type $\mathrm{Ca}^{(2+)}$ channels are essential for glutamate-mediated CREB phosphorylation and c-fos gene expression in striatal neurons. J Neurosci 19:6348-6359.

Randall A, Benham CD (1999) Recent advances in the molecular understanding of voltage-gated $\mathrm{Ca}^{2+}$ channels. Mol Cell Neurosci 14:255-272.

Sah P (1996) $\mathrm{Ca}^{(2+)}$-activated $\mathrm{K}+$ currents in neurones: types, physiological roles and modulation. Trends Neurosci 19:150-154.

Shankar S, Teyler TJ, Robbins N (1998) Aging differentially alters forms of long-term potentiation in rat hippocampal area CA1. J Neurophysiol 79:334-341.

Shieh PB, Hu SC, Bobb K, Timmusk T, Ghosh A (1998) Identification of a signaling pathway involved in calcium regulation of BDNF expression. Neuron 20:727-740.

Shitaka Y, Matsuki N, Saito H, Katsuki H (1996) Basic fibroblast growth factor increases functional L-type $\mathrm{Ca}^{2+}$ channels in fetal rat hippocampal neurons: implications for neurite morphogenesis in vitro. J Neurosci 16:6476-6489.

Sigworth FJ, Sine SM (1987) Data transformations for improved display and fitting of single-channel dwell time histograms. Biophys $\mathrm{J}$ 52:1047-1054.

Slesinger PA, Lansman JB (1991) Reopening of $\mathrm{Ca}^{2+}$ channels in mouse cerebellar neurons at resting membrane potentials during recovery from inactivation. Neuron 7:755-762.

Slesinger PA, Lansman JB (1996) Reopening of single L-type $\mathrm{Ca}^{2+}$ channels in mouse cerebellar granule cells: dependence on voltage and ion concentration. J Physiol (Lond) 491:335-345.

Snutch TP, Tomlinson WJ, Leonard JP, Gilbert MM (1991) Distinct calcium channels are generated by alternative splicing and are differentially expressed in the mammalian CNS. Neuron 7:45-57.

Soldatov NM (1994) Genomic structure of human L-type $\mathrm{Ca}^{2+}$ channel. Genomics 22:77-87.

Soldatov NM, Bouron A, Reuter H (1995) Different voltage-dependent inhibition by dihydropyridines of human $\mathrm{Ca}^{2+}$ channel splice variants. J Biol Chem 270:10540-10543.

Stuart G, Schiller J, Sakmann B (1997) Action potential initiation and propagation in rat neocortical pyramidal neurons. J Physiol (Lond) 505:617-632.

Tao X, Finkbeiner S, Arnold DB, Shaywitz AJ, Greenberg ME (1998) $\mathrm{Ca}^{2+}$ influx regulates BDNF transcription by a CREB family transcription factor-dependent mechanism. Neuron 20:709-726.

Thibault O, Landfield PW (1996) Increase in single L-type calcium channels in hippocampal neurons during aging. Science 272:1017-1020.

Thibault O, Porter NM, Landfield PW (1993) Low $\mathrm{Ba}^{2+}$ and $\mathrm{Ca}^{2+}$ induce a sustained high probability of repolarization openings of L-type $\mathrm{Ca}^{2+}$ channels in hippocampal neurons: physiological implications. Proc Natl Acad Sci USA 90:11792-11796.

Triggle DJ (1999) The pharmacology of ion channels: with particular reference to voltage-gated $\mathrm{Ca}^{2+}$ channels. Eur J Pharmacol 375: 311-325.

Tsubokawa H, Ross WN (1997) Muscarinic modulation of spike backpropagation in the apical dendrites of hippocampal CA1 pyramidal neurons. J Neurosci 17:5782-5791.

Weisskopf MG, Bauer EP, LeDoux JE (1999) L-type voltage-gated calcium channels mediate NMDA-independent associative long-term potentiation at thalamic input synapses to the amygdala. J Neurosci 19:10512-10519.

Westenbroek RE, Ahlijanian MK, Catterall WA (1990) Clustering of L-type $\mathrm{Ca}^{2+}$ channels at the base of major dendrites in hippocampal pyramidal neurons. Nature 347:281-284.

Yeckel MF, Kapur A, Johnston D (1999) Multiple forms of LTP in hippocampal CA3 neurons use a common postsynaptic mechanism. Nat Neurosci 2:625-633.

Zheng W, Rampe D, Triggle DJ (1991) Pharmacological, radioligand binding, and electrophysiological characteristics of FPL 64176, a novel nondihydropyridine $\mathrm{Ca}^{2+}$ channel activator, in cardiac and vascular preparations. Mol Pharmacol 40:734-741.

Zuhlke RD, Bouron A, Soldatov NM, Reuter H (1998) $\mathrm{Ca}^{2+}$ channel sensitivity towards the blocker isradipine is affected by alternative splicing of the human alpha1C subunit gene. FEBS Lett 427:220-224. 